\title{
TRABALHAR É VIVER E TER SAÚDE! CONCEPÇÕES DE QUILOMBOLAS DO RECONCAVO DA BAHIA
}

\author{
Jaianne Souza da Silva ${ }^{1}$ \\ Laine Soares Carvalho ${ }^{2}$ \\ Sânzia Bezerra Ribeiro ${ }^{3}$ \\ Evanilda Souza de Santana Carvalho ${ }^{4}$ \\ Cleuma Sueli Santos Suto ${ }^{5}$
}

Resumo: Este estudo teve como objetivo apreender as concepções de indivíduos quilombolas acerca do trabalho. Pesquisa exploratória e qualitativa com 49 membros de duas comunidades quilombolas do Recôncavo Baiano. A coleta se deu por entrevista semiestruturada, os resultados foram processados pelo software IRAMUTEQ que gerou gráficos e possibilitou a identificação de sete classes, nomeadas em acordo ao conteúdo das palavras que as compõem. A descrição do trabalho e rotina revela-se como caminho natural para aquisição de bens de consumo, ser honrado e útil, estando associado a viver e ter saúde, porém, foi reconhecido como difícil e pesado. Para os quilombolas, as inadequações físicas do trabalho se constituem como determinante do processo de saúde-

\footnotetext{
${ }^{1}$ Fisioterapeuta pela Faculdade Adventista da Bahia (FADBA). E-mail: jaianne.jr@hotmail.com

2 Fisioterapeuta pela Faculdade Adventista da Bahia (FADBA). E-mail: laysoaresfisio@hotmail.com

${ }^{3}$ Docente da FADBA (Faculdade Adventista da Bahia), Doutoranda do Programa em Enfermagem e SaúdeUFBA. Mestre em Engenharia da Produção-UFPB. Pós Graduada em Reeducação Postural Global Sensoperceptiva - FIC (Faculdade Integrada do Ceará). Pós Graduada em Saúde Pública pela FADBA. Email: sanziar@gmail.com
}

4 Graduada em Enfermagem pela Universidade Estadual de Feira de Santana (1990). Doutora em Enfermagem pela UFBA (2010), com Doutorado Sanduich no Departamento de Sociologia IV da Universidad Complutense de Madrid (2009-2010). Mestrado em Enfermagem pela Universidade Federal da Bahia (2005). Pós doutorado no College of Nursing - University of South Carolina, Columbia - Estados Unidos. (2018-2019) Bolsista CNPq. Docente nos cursos de Graduação em Enfermagem, e Pós graduação em Enfermagem e em Saúde Coletiva da Universidade Estadual de Feira de Santana. E-mail: evasscarvalho@yahoo.com

5 Enfermeira (UEFS). Doutora em Enfermagem e Saúde pela Escola de Enfermagem (UFBA). Mestra em enfermagem (UFBA), Especialista em Obstetrícia e Saúde Pública (UEFS). Professora Assistente da Universidade do Estado da Bahia (UNEB), Campus VII. Integrante do Grupo de Pesquisa Saúde da mulher, gênero e integralidade do cuidado. E-mail: cleuma.suto@gmail.com 
doença. Faz-se necessário implementação de ações que os orientem sobre a influência dos aspectos do trabalho em sua saúde.

Palavras chave: Concepções do trabalho, Quilombolas, Trabalho rural.

\title{
TO WORK IS TO LIVE AND HAVE HEALTH! BAHIA RECONCAVO QUILOMBOLA CONCEPTIONS
}

\begin{abstract}
This study aimed to grasp the conceptions of quilombola individuals about work. Exploratory and qualitative research with 49 members from two quilombola communities of Recôncavo Baiano. The collection was made through semi-structured interviews, the results were processed by the IRAMUTEQ software that generated graphs and allowed the identification of seven classes, named in acronym to the content of the words that compose them. The job description and routine is revealed as a natural way to purchase consumer goods, to be honorable and useful, being associated with living and being healthy, however, was recognized as difficult and heavy. For quilombolas, the physical inadequacies of work constitute a determinant of the health-disease process. It is necessary to implement actions that guide them about the influence of work aspects on their health.
\end{abstract}

Keywords: Conceptions of work, Quilombolas, Rural work.

\section{¡TRABAJAR ES VIVIR Y TENER SALUD! BAHIA RECONCAVO CONCEPCIONES QUILOMBOLAS}

Resumen: Este estudio tuvo como objetivo comprender las concepciones de los individuos de quilombola sobre el trabajo. Investigación exploratoria y cualitativa con 49 miembros de comunidades quilombolas de Recôncavo Baiano. La recopilación se realizó mediante entrevista semiestructurada, los resultados fueron procesados por el software IRAMUTEQ que generó gráficos y permitió la identificación de siete clases, nombradas en acrónimo del contenido de las palabras que las componen. La descripción del trabajo y la rutina se revela como una forma natural de comprar bienes de consumo, para ser honorable y útil, está asociado con la vida y la salud, sin embargo, se reconoció como difícil y pesado. Para las quilombolas, las deficiencias físicas del trabajo constituyen un determinante del proceso salud-enfermedad. Es necesario implementar acciones que los guíen sobre la influencia de los aspectos laborales en su salud.

Palabras clave: Concepciones de trabajo, Quilombolas, Trabajo rural.

\section{TRAVAILLER, C'EST VIVRE ET AVOIR LA SANTÉ! CONCEPTIONS DES QUILOMBOLAS BAHIA RECONCAVO}

Résumé: Cette étude visait à comprendre les conceptions des individus quilombola sur le travail. Recherche exploratoire et qualitative avec 49 membres de deux communautés quilombola du Recôncavo Baiano. La collecte a été réalisée à travers des entretiens semistructurés, les résultats ont été traités par le logiciel IRAMUTEQ qui générait des graphes et permettait l'identification de sept classes, nommées en sigle pour le contenu des mots qui les composent. La description de poste et la routine se révèlent être un moyen naturel d'acquérir des biens de consommation, d'être honorable et utile, d'être associé à la vie et

Revista da ABPN • v. 12, n. $31 \cdot \operatorname{dez} 2019$ - fev 2020, p. 410-427 
à la santé, mais il a été reconnu comme difficile et pesant. Pour les quilombolas, les insuffisances physiques du travail constituent un déterminant du processus santé-maladie. Il est nécessaire de mettre en œuvre des actions qui les guident sur l'influence des aspects professionnels sur leur santé.

Mots cles: Conceptions du travail, Quilombolas, Travail rural.

\section{INTRODUÇÃO}

Quilombolas, entende-se por indivíduos remanescentes das comunidades dos quilombos, reconhecidos pelo artigo $2^{\circ}$ do Decreto $n^{\circ} 4.88727$ como "grupos étnicoraciais, segundo critérios de auto atribuição, com ancestralidade negra e trajetória histórica própria, dotados de relações territoriais específicas” (BRASIL, 2002)

Os quilombos são definidos, não apenas como o grande espaço de resistência guerreira, territórios representantes de recursos radicais de sobrevivência grupal, com uma forma comum de vida e modos próprios de organização. E tornaram se o lugar de refúgio dessa população, representando assim a concretização da busca incessante por um lugar no qual pudessem desenvolver suas práticas culturais e atividade rurais. De modo que com o passar do tempo os integrantes da comunidade começavam a adquirir afetividade e identidade por esse local que estavam inseridos. (GOMES et al, 2013; VERONEZZI et al. 2013).

Estima-se que no Brasil há 214 mil famílias e 1,17 milhões de quilombolas, distribuídos nos diversos Estados brasileiros, num total 2.040 comunidades certificados pela Fundação Cultural Palmares, sendo 63\% delas localizadas no Nordeste (FREITAS et. al, 2018). Os indivíduos que integram essas comunidades estão vinculados por fortes laços culturais, mantendo suas tradições, práticas religiosas, relação com o trabalho na terra e sistema de organização social (FERREIRA \& TORRES. 2015).

Estudo com quilombolas do estado do Rio de Janeiro possibilitou identificar que muitas das condições de trabalho eram precarizadas, principalmente, em decorrência de não terem a posse legal da terra e por venderem sua força de trabalho em condições informais, sem vínculos trabalhistas, a proprietários das fazendas nos arredores. Nesse sentido, os autores já apontavam que a condição de informalidade e o regime de trabalho contratual são elementos que necessitam de verificação quanto a seus significados ao se pesquisar trabalho na perspectiva dos quilombolas (LOPES et al, 2008). 
O trabalho é repleto de sentido tanto individual quanto social, pode ser um recurso de produção da vida de cada um ao criar sentidos a existência, colaborar para a estruturação da identidade e da subjetividade (TOLFO \& PICCININI, 2007), tem papel essencial na criação de recursos e no desenvolvimento de sociedades (RIBEIRO, 2005).

Devido a maior inserção da população negra no mercado informal, em especial no trabalho rural, as condições de precariedade do trabalho configuram-se num dos principais aspectos de vulnerabilidade a saúde desses indivíduos (PRONI \& GOMES 2015; BRASIL MS 2018).

Este artigo foi guiado pela seguinte questão de pesquisa: Como pessoas de comunidades quilombolas concebem o trabalho e constroem sentido para seu exercício. Para responder a essa questão este artigo teve por objetivo: Apreender as concepções de indivíduos quilombolas acerca do trabalho.

\section{METODOLOGIA}

Trata-se de uma pesquisa de natureza qualitativa de caráter exploratório, realizada em duas comunidades quilombolas, Mutecho e Opalma pertencentes a região de Santiago do Iguape no município de Cachoeira, Bahia e a $110 \mathrm{Km}$ da cidade de Salvador, BA, Brasil. O estudo atendeu às recomendações da Resolução 466/2012 do Conselho Nacional de Saúde, registrado sob CAAE 86768318.6.0000.042 e foi aprovado pelo Comitê de Ética através do parecer de número 199.777.

Participaram desta pesquisa 49 indivíduos, de acordo com os seguintes critérios: ter acima de 16 anos, ser de ambos os sexos e que exercessem qualquer atividade ocupacional. Foram excluídos aqueles que não compreenderam as perguntas, ou não foram encontrados em casa. A coleta de dados se deu por meio de entrevistas semiestruturadas, aplicadas por quatro pesquisadores, três alunos graduandos em fisioterapia, e um docente orientador do trabalho, devidamente treinados. As entrevistas foram gravadas, com duração de 7 a 13 minutos, em maio de 2018, após cada participante assinar o Termo de Consentimento Livre e Esclarecido (TCLE). A transcrição das entrevistas foi realizada pelos pesquisadores.

Os dados obtidos por meio das entrevistas extraíram respostas para as seguintes perguntas: “O que trabalhar significa para você?”, "O que não trabalhar significa para 
você?", "Que atividades de trabalho você consegue fazer? Que atividades do seu trabalho tem dificuldade ou não consegue fazer?" Passaram por analise através do Software IRAMUTEQ (Interface de $R$ pour les Analyses Multidimensionnelles de Textes et de Questionnaires), desenvolvido por Pierre Ratinaud em 2009 e licenciado por GNU GPL (v2), que permite fazer análises estatísticas sobre corpus textuais e sobre tabelas, indivíduos/palavras (Kami et. al, 2016; CAMARGO \& JUSTO 2013 e SALVIATI, 2017); , análises estas que foram complementadas pela análise de conteúdo realizada pelas pesquisadoras.

Para obter os resultados da análise qualitativa no Software IRAMUTEQ, utilizouse textos advindos das entrevistas $(\mathrm{N}=49)$ contendo a transcrição realizada para a formação do corpus textual, após processo da lematização. Utilizou-se como frequência mínima 8 e apenas as palavras classificadas como substantivos, verbos e advérbios, as demais classes de palavras foram excluídas. Os dados da figura 1 resultaram da Classificação Hierárquica Descendente (CHD) que gerou um dendograma com sete classes. O software criou subagrupamentos até as ramificações finalmente mostrarem-se estáveis. Os dados contidos na figura 2 configuram, por meio da Análise Fatorial de Correspondência (AFC), a observação das oposições e aproximações de palavras sob a forma de um plano fatorial. Na AFC o primeiro fator (F1) explica 22,2 \% da inércia total e possui valor próprio de 0,065434 ; o segundo fator (F2) explica 23,6\% da inércia total, com valor próprio de 0,065531, possibilitando, também, apresentar as variáveis que compuseram cada uma das classes.

Para melhor elucidação do sendo dos léxicos presentes na CHD e AFC utilizaremos recorte de fala das/os participantes. A fim de preservar o anonimato as falas foram identificadas com a letra "P", seguida de sexo (H=homem e $\mathrm{M}=$ mulher).

\section{RESULTADOS}

Dos 49 quilombolas participantes deste estudo, 61\% eram do sexo feminino e $38,8 \%$ masculino, tinham idades que variavam entre 16 e 75 anos, apresentando faixa etária com maior percentual entre 36 a 59 anos (38,8\%), sendo que 4,1\% não souberam responder a idade. 
Quanto ao tipo de trabalho realizado, classificado pela CBO (Classificação Brasileira de Ocupações), destacam-se as atividades de trabalhador volante da agricultura (34,7\%), seguido de empregado doméstico (32,7\%) e trabalhador na agricultora de dendê $(26,5 \%)$. Um pouco mais da metade dos trabalhadores relataram exercer suas atividades ocupacionais em uma jornada de 5 a 8 horas (51\%). Ao serem questionados quanto a presença de desconfortos durante a jornada de trabalho, 67,3\% responderam sim, sendo que a principal queixa foi a dor $(55,1 \%)$, seguida de fraqueza e vertigem que somam 12,2\%. 32,7\% relataram não sentir nenhum incômodo e um total de 46,9\% consideraram que seu trabalho era o causador destes desconfortos.

Figura 1. Dendograma para Classificação Hierárquica Descendente de Quilombolas, fornecidas pelo software IRAMUTEQ - Feira de Santana, BA, 2019.

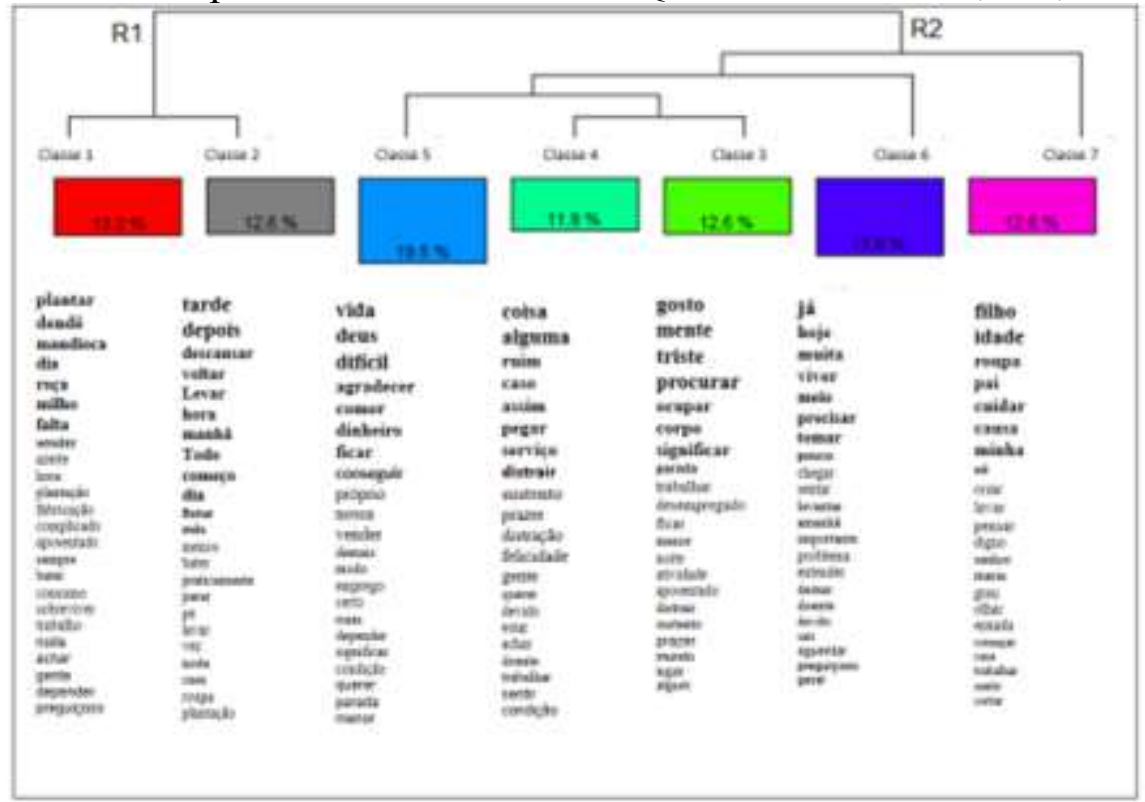




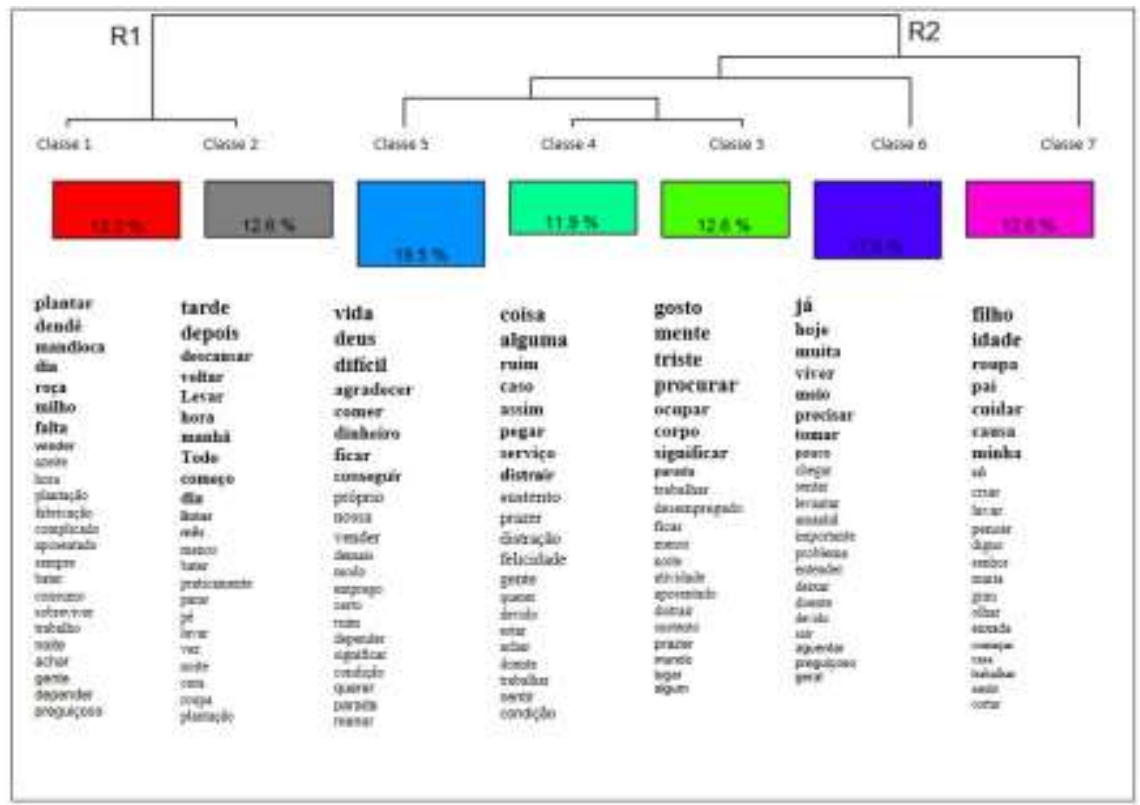

A análise do Dendograma possibilitou a identificação das sete classes de palavras indicando contextualização do sentido atribuído às mesmas, auxiliando, assim, na identificação das concepções de quilombolas. A CHD organizou a distribuição do vocabulário, advindo das respostas das/os 49 participantes, de forma facilmente compreensível e visualmente clara. Neste estudo, utilizou-se como ponto de corte a frequência igual ou superior a 8 no corpus analisado.

No Dendograma da CHD, observam-se que duas ramificações semânticas formadas a partir da conformação do corpus textual, considerando as palavras com maior frequência e p ( $p$-value) de 0,0001. Encontra-se na primeira ramificação (R1) as classes $1(13,2 \%)$ e $2(12,6 \%)$; e, na segunda ramificação (R2) a subdivisão das classes 7(12,6\%), $6(17,6 \%), 5(19,5 \%), 4(11,9 \%)$ e $3(12,6 \%)$ (Figura 1).

As palavras, agrupadas em lista e diferenciadas por tamanho, possibilitam uma visualização quanto a sua influência nas classes, assim, quanto mais no topo e maior o seu tamanho, mais destaque ela terá apresentado no corpus textual (RAMOS et al., 2018). As representações dos sujeitos que compõem as classes 1 e 2, na R1, apresentam aproximação entre si frente as demais classes. Em R1, as classes são formadas por palavras como: "plantar, dendê e mandioca" (classe 1), e, "tarde, descansar e começo" (classe 2). Por outro lado, em R2, na classe 7, filho, idade e cuidar, geraram uma desconecção entre esta e as demais classes, caracterizando-a como classe solitária de um lado com subcorpus do outro, formados pelas classes $6,5,4$ e 3 . A classe 6 contendo as 
palavras como, "hoje e viver", de um lado e do outro, a classe 5 formada por termos como, "vida, deus e difícil”. Na última partição, palavras como, "coisa, alguma, e ruim" na classe 4 e "gosto, mente e triste" na classe 3 concluem o conteúdo lexical dessa ramificação.

A Figura 2 apresenta as mesmas sete classes da CHD e sua distribuição em quadrantes por meio da Análise Fatorial de Correspondência (AFC) sob a forma de um plano fatorial. Nos quadrantes à direita, distribuem-se as contribuições das classes 1 e 2 (R1), com tendência de aproximação no eixo horizontal (abcissa). No quadrante inferior à esquerda a classe 7 em oposição às demais e mais agrupadas ao quadrante superior à esquerda, próximas à origem dos eixos, estão posicionadas palavras provenientes das classes $3,4,5$ e 6 (R2).

Figura 2. Análise fatorial de correspondência dos sujeitos de Quilombolas, fornecidas pelo software IRAMUTEQ - Feira de Santana, BA, 2019.

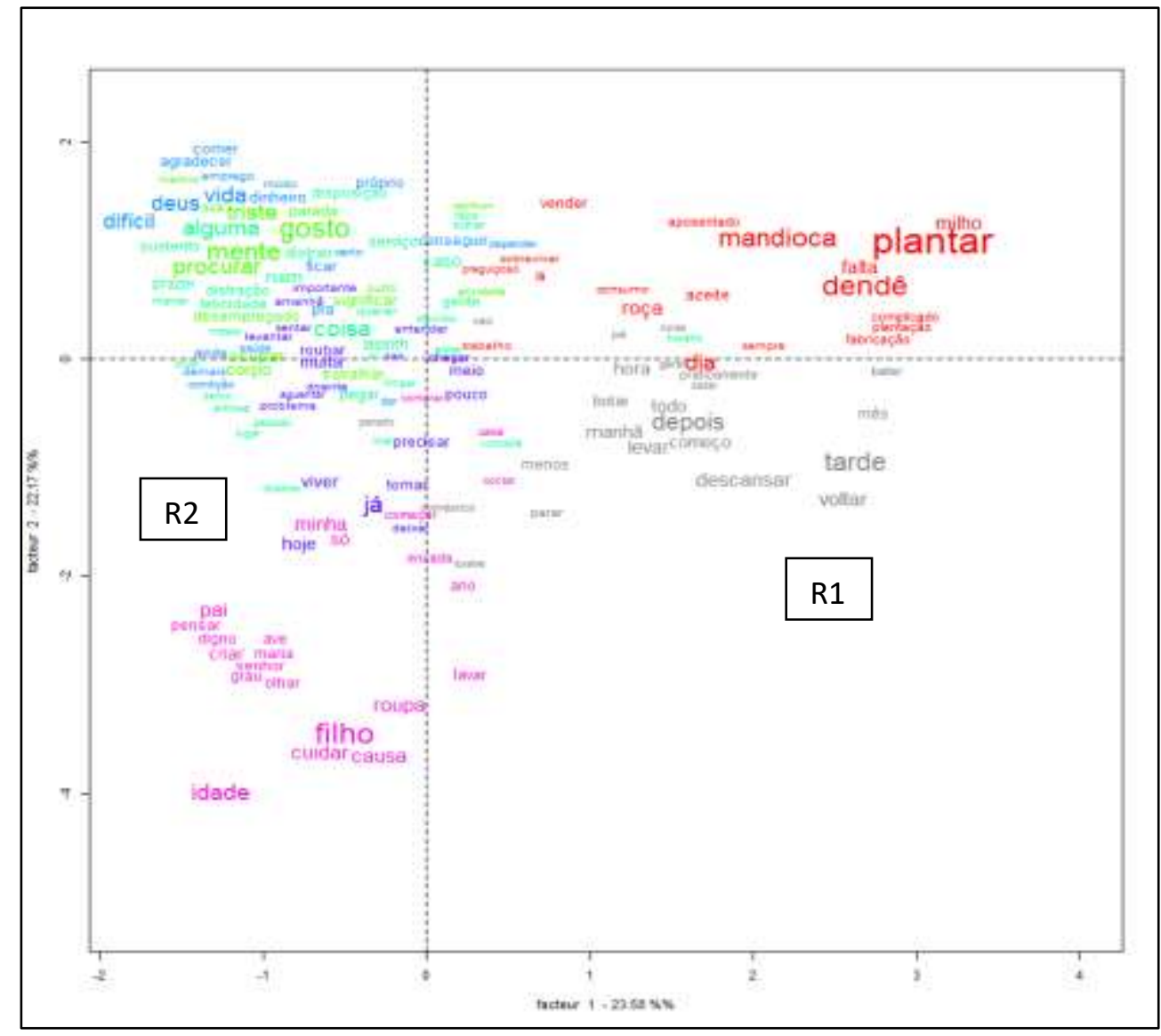

Revista da ABPN • v. 12, n. $31 \cdot \operatorname{dez} 2019$ - fev 2020, p. 410-427 
A classe 1, denominada pelas pesquisadoras de "descrição do tipo de trabalho", e a classe 2, "rotina do trabalho" agrupam falas como:

- Trabalho de enxada, trabalho de machado, trabalho de facão, trabalho de estrovenga. É na roça, lá na roça. (P14, H).

- Trabalho na roça plantando mandioca, essas coisas assim, é para o consumo também, quando as coisa aperta a gente vende também. (P12, M)

- Trabalho de casa e no dia-a-dia, que eu mais meu marido a gente faz o azeite de dendê, aqui do lado tem até uns dendês que a gente está fazendo [...]. É o dia todo viu, começo a trabalhar umas 6 horas da manhã que é para catar o fruto todo, botar no fogo, bater o azeite. Ali está o que fizemos ontem, aí cata, depois bota para cozinhar, depois vai, depois que cozinha, vai pisar e depois que pisa leva para fora para bater, depois que bate tirar aquela nata que sobe aí depois pega e faz o azeite. Ai tempera todo para depois pôr na garrafa e nós sair para vender, a gente está trabalhando de segunda-feira a sábado. (P7, M).

Palavras que identificam o trabalho doméstico, como lavar, roupa e casa também estão presentes na descrição da rotina, porém, citadas apenas por mulheres.

- Aqui eu faço tudo, varro casa, lavo prato, cozinho, lavo roupa, e de vez em quando vou na roça, agora, não é serviço pesado na roça. Plantando maxixe, planto quiabo, aquelas covinhas de quiabo, só serviço de dia-a-dia aqui perto de casa, as vezes planto a manaíba, agora não faço serviço muito de enxada porque depois que tive artrose não tenho condição e fazer esse serviço, eu faço esse serviço assim, mais aliviado (P15, M)

Interessante notar que as mesmas palavras, "roupa, casa e lavar" aparecem novamente na classe 7, denominada "trabalho associado às práticas de cuidado" em maior destaque e juntamente com outras como "filho, idade, cuidar e pai".

As classes 3, 4 e 5, que foram denominadas de forma respectiva, "relação do indivíduo com o seu trabalho", "o significado do trabalho" e "a razão de se trabalhar" se apresentam aglutinadas na AFC (R2), sendo que o significado do trabalho e a razão de se trabalhar estiveram intimamente catalogados nos discursos dos trabalhadores, relacionado a razão 
de se trabalhar principalmente à vida. No entanto, demonstram relação com a necessidade de sustento, prazer ou satisfação, distração ou ocupação da mente, melhora da condição de vida e geração de mais disposição e menos doenças, expressões usadas pelos próprios entrevistados com declarações como:

- [...] não trabalhar significa, significa uma vida ruim, sei lá, significa uma vida sem destino, uma vida assim ao deus dará, a pessoa sem trabalhar não é vida não, você tem que ter o trabalho. $(\mathrm{P} 7, \mathrm{M})$

- Eu gostaria de ter um trabalho, é assim a gente tem a possibilidade de ter uma vida melhor [...]. (P8, M)

- Trabalhar significa parte da nossa vida, crescimento, beneficio também geração de dinheiro (...). (P18, $\mathrm{H})$

- Ah o trabalho é muito importante na nossa vida [...]. Não trabalhar, Ave Maria, piora tudo, vai viver de que, Ave Maria, é, roubar ninguém pode e o bom é o seu, não o dos outros, então o trabalho é muito importante [...]. (P32, M)

- Trabalhar significa independência, é, uma maneira de a gente conseguir com nossos esforços ter uma condição de vida melhor pra poder conquistar nossa liberdade, conquistar nossa independência também, ficar livre assim de algumas coisas de responsabilidade dos pais, e também, é pra gente poder se manter também, as coisas que a gente precisa [...]. (P35, H).

A classe 6, integra principalmente as respostas usadas para "o significado do nãotrabalho", muitas vezes associados a doença, preguiça, problema e caminho para o roubo, mostrando que esses indivíduos entendem que o trabalho os dignifica, traz saúde e mostra que a vida vai bem, porém quando não trabalham, sentem-se como doentes, frustrados, inúteis e dependentes, como mostram suas declarações.

- Não trabalhar eu acho ruim, se você não faz nada está inútil assim [...]. (P17, M)

- Não trabalhar é ruim porque a gente fica sem poder fazer nada, dependente de alguém para fazer e aí para mim fica difícil, porque não aguento ver e não poder fazer sabe [...]. (P27, M) 
- Não trabalhar é estar doente, se não puder fazer as coisas está doente, ou vai dá para roubar [...]. (P28, H).

\section{DISCUSSÃO}

Serão discutidas incialmente a ramificação 1 (R1) formada pela classe 1, denominada de "descrição do tipo de trabalho", e classe 2, "rotina do trabalho". Em seguida, a ramificação 2 (R2) composta pelas classes 3, 4 e 5, denominadas respectivamente de "relação do indivíduo com o seu trabalho", "o significado do trabalho" e "a razão de se trabalhar terão suas considerações. Só então, nesta mesma ramificação, as casses 6 , "o significado do não-trabalho" e a classe 7 significando o "trabalho associado às práticas de cuidado" serão discutidas.

Pôde-se constatar, por meio da observação da CHD (Figura 1), que a descrição do tipo de trabalho e suas a rotinas aparecem interligadas na R1, evidenciando a dinâmica da agricultura familiar no local, seja na plantação de mandioca e do milho, ou no cultivo do dendê para a fabricação de azeite sendo todas as fases do processo realizadas dentro da própria comunidade, por homens e mulheres, como fonte de renda para grande parte das famílias. Vale salientar que a lida com a plantação exige que sua rotina se inicie logo cedo, com pausa para o almoço e retorno pela tarde por mais algumas horas.

As relações de trabalho nas comunidades quilombolas encontram-se configuradas em termos de apropriação da terra numa relação harmônica entre natureza e cultura. Nesse sentido, o trabalho e seu resultado incidem sobre os próprios sujeitos, por não haver, na perspectiva de Marx a apropriação de meios de produção que não seja pelo próprio sujeito trabalhador. Assim, para os quilombolas, o trabalho é feito por ele e para ele, e portanto, não trabalhar implicaria em uma responsabilidade do sujeito do quilombo para consigo mesmo, sua liberdade, e sua saúde tanto física quanto mental (SOUSA \& SANTOS, 2019).

Ao falar sobre a qualidade de vida dos trabalhadores rurais em Pernambuco, um estudo aponta que a agricultura familiar, praticada por homens, mulheres e crianças, diariamente em situações precárias de trabalho, sem equipamentos adequados, produzindo alimentos de baixa rentabilidade, sem assistência, associados a moradia insalubre, baixa escolaridade e alimentação deficiente, caracteriza o universo existencial 
de famílias do campo (SIQUEIRA \& MOURA, 2012). Especificamente na cultura do Dendê, outro estudo revela que a precariedade a que estão sujeitos os trabalhadores, interfere inclusive, na constituição de uma família, pelo tempo de ausência dos trabalhadores de seu lar (FERREIRA, 2016).

Um estudo sobre a organização do trabalho familiar na cultura do dendê no Pará, aponta que o trabalho é amparado em relações de gênero e de geração, e dar-se em sintonia com o ciclo de desenvolvimento do grupo doméstico e com a destinação e utilização do produto final, além, das influências externas (MOTA et. al, 2019). Sobre o trabalho rural, outro estudo aponta em sua pesquisa que todos os seus entrevistados são autônomos, sem vínculo com a Previdência Social, trabalham de segunda a sábado, de $07 \mathrm{~h}$ às $17 \mathrm{~h}$, com pausa de uma a duas horas para o almoço, e recebem um rendimento mensal em torno de um salário mínimo(MIRANDA et. al, 2020). Para os/as quilombolas, em seus discurso, parece haver uma invisibilização das relações de trabalho e do aparato social de suporte ao trabalhador, o que corrobora com o estudo realizado na comunidade quilombola de Abacatal, Pará, onde os recursos provenientes a partir da produção agrícola familiar são insuficientes para suprir as necessidades das famílias e os benefícios sociais e aposentadorias acabam por assumir papel importante na sustentação dessas famílias (ARAÚJO et al, 2017).

A ramificação 2, esboça em parte de seu conjunto (classes 3, 4 e 5) a relação do indivíduo com o seu trabalho, o significado e suas razões. Apontam a necessidade de sustento como um elemento primordial e destacam sentimentos de prazer/satisfação. Parece haver um entendimento de que trabalho significa, para os/as participantes, a condição primordial para melhoria da qualidade e situação de vida. Essas considerações foram encontradas em outros estudos com trabalhadores rurais que destacam que ter um trabalho que pague as contas e garanta o sustento da família configura-se como um dos principais aspectos da qualidade de vida no trabalho (RIBEIRO, 2005; FOLADOR, 2018). Outro entendimento, perpassa o significado de disposição física e menos doenças, expressões marcadas em suas falas.

Mesmo com as mudanças associadas ao trabalho ao longo da história, sua importância na formação da subjetividade e identidade dos indivíduos e sua influência na construção das sociedades são evidentes. Desse modo, pode-se considerar que o sentido 
do trabalho é originário de uma historicidade e está em consonância com a época, cultura, modo de se relacionar e compreender o mundo (NEVES et. al, 2018).

Utilizando a perspectiva de Morin ao definir o sentido do trabalho enquanto estrutura afetiva que se forma a partir de três componentes: significado, orientação e coerência, o significado se refere às imagens que o sujeito tem de sua atividade e o valor a ele atribuído (MORIN et. al, 2007). Nessa perspectiva, os participantes parecem compactuar com uma imagem elaborada a partir do ponto mais básico para o ser humano - satisfação de necessidades básica e manutenção da vida. A qualidade de vida no trabalho pode ser identificada a partir de oito critérios que contribuem para uma maior motivação e satisfação com o trabalho (MOURA \& SOUZA, 2016). Nesse estudo, a remuneração justa e adequada; saúde e segurança no trabalho; e, a oportunidade imediata para a utilização e desenvolvimento da capacidade humana no aspecto autonomia foram os principais critérios apontados enquanto interferência direta na qualidade de vida no trabalho dos quilombolas.

As normas sociais sobre o trabalho laboram como arquétipos sociais que dizem respeito às possíveis recompensas obtidas pelo trabalho, o que vem a gerar no trabalhador a percepção do que seriam trocas justas, ou seja, o que o trabalhador recebe como pagamento pelo seu trabalho e as contribuições que ele traz. Assim, os motivos que levam uma pessoa a trabalhar são: retorno financeiro, manter-se em atividade, sentir-se útil para a sociedade, entre outros (NEVES et al, 2018). Os arquétipos sociais e motivos apresentados coadunam com os discursos dos quilombolas.

As concepções dos/as participantes apresentam um jogo de oposições entre trabalhar e ter saúde, com não trabalhar e estar doente, atribuindo o significado de saúde como consequência do trabalho. Nessa perspectiva, em estudo realizado com trabalhadores rurais de uma fazenda do sul do Brasil, demonstrou-se que o significado de qualidade de vida no trabalho para os trabalhadores também estava relacionado a ter saúde (FOLADOR, 2018). Outros estudos apontam o setor agrícola como um dos ramos produtivos onde o trabalhador está mais exposto a riscos ergonômicos, os quais contribuem para o desenvolvimento de distúrbios osteomioarticulares e incapacidades (RIBEIRO, 2005; DAVIS \& KOTOWSKI, 2007; DIAS, 2006; DRISKOLL et al 2014).

A presença de doenças crônicas em população quilombola esteve associada com a autopercepção negativa sobre saúde por parte do indivíduo. Os autores consideraram 
que ela pode estar relacionada ao fato de doenças como hipertensão, diabetes e doenças inflamatórias como artrite e artrose alterarem os hábitos e implicando assim sobre a capacidade produtiva dos indivíduos levando-o consequentemente ao sentimento de menor valia (OLIVEIRA et.al, 2015).

A segunda parte da R2, abarcando a classes 6 com o não-trabalho e, a classe 7 com o trabalho associado às práticas de cuidado é demarcado pelas palavras como: "roupa, casa, lavar, filho, idade e cuidar" (classe 7) e com relação direta com "meio de viver, necessidade e importância". Parece apontar para um trabalho "entendido" enquanto "feminino" pois entende-se que as mulheres que trabalham em casa, no serviço doméstico, o fazem porque são as responsáveis pela organização do lar e muitas vezes não podem trabalhar fora, pois estão envolvidas diretamente o cuidado de manutenção da vida na criação dos filhos, ou quando na posição de filhos cuidando de seus pais. Quando citaram realizar atividade diferente da doméstica muitas eram associadas à agricultura e ao processo de fabricação do azeite. Numa perspectiva de gênero, as mulheres quilombolas, neste estudo, em seus relatos, ainda, associaram o significado de trabalho ao prazer e diversão, como sendo uma possibilidade de passar o tempo na comunidade.

Além da atividade doméstica, as mulheres também participam do trabalho, principalmente na produção do azeite e na agricultura. O que remeteu à compreensão de que elas executam uma dupla jornada com atividades dentro e fora do espaço doméstico. O modelo familiar, presente no contexto quilombola estudado, possui traços de uma cultura androcêntrica em que é atribuída à mulher a responsabilidade do cuidado com a casa e com os filhos. Estudo realizado em Pernambuco com mulheres jovens quilombolas sobre suas vivências em relação a família e ao trabalho apontam no mesmo sentido (SILVA \& MENEZES, 2015).

As relações e deliberações diversas do cotidiano familiar, no meio rural, manifestam o modelo de relações hierárquicas entre homens e mulheres, onde a figura masculina representa o centro das decisões e do poder, como aponta estudo envolvendo trabalhadores rurais de Minas Gerais (MIRANDA et. al, 2020). O trabalho das mulheres no Brasil, quando analisado numa perspectiva feminista, nos instiga a pensar na seguinte afirmação "passados cem anos, ainda se tem como norte as reivindicações por trabalhos dignos e saudáveis" onde as explorações a que trabalhadoras estão submetidas evidenciam uma sociedade desigual (ANDRADE, 2019). Nesse sentido, estudo 
envolvendo mulheres residentes em favelas situadas na cidade de Talcahuano no Chile, reconhece que a heterogeneidade das práticas econômicas realizadas pelas mulheres em torno da economia familiar, dos cuidados e da manutenção da vida familiar, compreendida como economia solidária é essencial e se mantem na contra mão do neoliberalismo (AGUAYO \& RAMIREZ 2019).

Buscando identificar estudos sobre a saúde da população quilombola nos últimos 10 anos, destacam-se como fatores determinantes que as comunidades quilombolas são marcadas pela exclusão social, onde cerca de $90 \%$ das famílias pertencem às classes sociais mais baixas e vivenciam maior presença de doenças crônico-degenerativas (CARDOSO et.al, 2018). Apesar das transformações sociais se refletirem em sentidos e modos plurais para o trabalho, esse continua a se configurar como importante determinante das condições de vida das pessoas, atravessando as diferentes esferas da vida de tal forma que se torna difícil estabelecer as fronteiras entre o trabalho e o não trabalho (SORJ, 2000).

\section{CONSIDERAÇÕES FINAIS}

O trabalho enquanto determinante social de saúde possui significados únicos em comunidades quilombolas. Na comunidade em estudo, possui características do trabalho rural com ênfase na agricultura familiar, porém com destaque para a cultura do dendê.

Observou-se que a descrição do tipo de trabalho e sua rotina fazem parte da compreensão desses significados, um caminho natural para aquisição de bens de consumo, e para se almejar uma vida melhor para si e para os filhos, ser honrado, ser útil e ter prazer no que se faz. Embora, reconheçam o trabalho como difícil e pesado, o mesmo associa-se a aspectos muito mais positivos do que negativos, uma vez que o significado de não trabalhar para eles foi associado a inutilidade, a preguiça, e uma vida sem propósito e enferma. A mulher quilombola vivencia o trabalho, apesar da dupla jornada" com mais "leveza" que os homens ao descreve-lo como "ocupa a mente" e "ajuda o tempo a passar".

As condições do trabalho observadas in loco e os relatos apresentados pelos quilombolas nos ajudam a identificar as inadequações físicas do trabalho como um determinante do processo de saúde-doença desses indivíduos, sendo necessário implantar ações que os orientem sobre a influência dos aspectos do trabalho na saúde física e mental 
na população quilombola já preconizadas na Política Nacional a Saúde Integral da População Negra.

\section{REFERÊNCIAS BIBLIOGRÁFICAS}

AGUAYO, Beatriz Eugenia Cid; RAMIREZ, Loreto Patricia Arias. La Economía Solidaria en la politización del trabajo escondido de las mujeres. Rev. Estud. Fem., v.27, n.2. 2019.

ANDRADE, Cristiane Batista. A história do trabalho das mulheres no Brasil: perspectiva feminista. Cad. Saúde Pública. v.35, n.2, 2019, p.1-3.

ARAÚJO, Allyne dos Santos et al. Análise socioeconômica de agricultores da comunidade quilombola do Abacatal, Ananindeua, estado do Pará, Brasil. Biota Amazônia. v. 7, n. 1, 2017 p. 30-37. Disponível em: <https://periodicos.unifap.br/index.php/biota/article/view/2466>. Acessado em: 28 de Outubro de 2019.

BRASIL, Ministério da Saúde (MS). Política Nacional de Saúde Integral da População Negra. Brasília: MS; 2007.2 Dísponível em: http://bvsms.saude.gov.br/bvs/publicacoes/politica_nacional_saude_integral_populacao.pdf.

Acessado em: 06 de Agosto de 2018.

BRASIL, Decreto No 4.887, de 20 de Novembro de 2003. Regulamenta o procedimento para identificação, reconhecimento, delimitação, demarcação e titulação das terras ocupadas por remanescentes das comunidades dos quilombos de que trata o art. 68 do Ato das Disposições Constitucionais Transitórias. Brasília, 2003. Disponível em: http://www.planalto.gov.br/ccivil_03/decreto/2003/D4887.html. Acessado em 24 de Novembro de 2019.

CAMARGO, Brigido Vizeu; JUSTO, Ana Maria. IRAMUTEQ: um software gratuito para análise de dados textuais. Temas psicol. v.21, n.2, 2013, p. 513-518.

CARDOSO, Clarissiane Serafim; MELO, Letícia Oliveira de; FREITAS, Daniel Antunes. Condições de saúde nas comunidades quilombolas. Rev enferm. v.12, n.4, 2018, p.1037-45. Disponível em: https://periodicos.ufpe.br/revistas/revistaenfermagem/article/viewFile/110258/28665. Acesso em: 18 de Outubro de 2018.

DAVIS, Kermit \& KOTOWSKI, Susan. Understanding the ergonomic risk for musculoskeletal disorders in the United States Agricultural Sector. American journal of industrial medicine. v.50, n.7, 2007, p.501-11. Disponível em: https://www.researchgate.net/publication/6324956_Understanding_the_ergonomic_risk_for_mu sculoskeletal_disorders_in_the_United_States_Agricultural_Sector. A Acessado em: ${ }^{-} 28$ de Outubro de 2019.

DIAS, Elizabeth Costa. Condições de vida, trabalho, saúde e doença dos trabalhadores rurais no Brasil. Condições de vida, trabalho, saúde e doença dos trabalhadores rurais no Brasil. 2006. Disponível em: http://www.luzimarteixeira.com.br/wp-content/uploads/2009/11/saudetrabalhador-rural.pdf. Acessado em: 03 de outubro de 2019. 
DRISCOLL T, et.al. The global burden of occupationally related low back pain: estimates from the Global Burden of Disease 2010 study. Ann Rheum Dis. v.73, n.6, 2014, p.75-981.

FERREIRA, Haroldo da Silva; TORRES, Zaira Maria Camerino. Comunidade quilombola na Região Nordeste do Brasil: saúde de mulheres e crianças antes e após sua certificação. Rev. Bras. Saude Mater. Infant. v.15, n.2, 2015, p. 219-229.

FERREIRA, Vanilda Araújo. As influências socioeconômicas e ambientais da cadeia produtiva do dendê no desenvolvimento local do Baixo Tocantins. Dissertação (Mestrado) - Universidade Federal do Pará, Núcleo de Altos Estudos Amazônicos, 2016. Disponível em: repositorio.ufpa.br/jspui/handle/2011/7846 $\&$ cd $=1 \&$ hl $=$ pt-BR\&ct $=$ clnk\&gl=br. Acessado em 28 de Outubro de 2019.

FOLADOR Mônica, qualidade de vida no trabalho rural: estudo de caso em uma propriedade agrícola de Campinas do Sul/RS. Trabalho de Conclusão de Curso em Administração. Universidade Federal do Rio Grande do Sul, 2018. Disponível em: https://lume.ufrgs.br/handle/10183/185027. Acessado em 28 de Outubro de 2019.

FREITAS, Igor Almeida de; RODRIGUES, Ivaneide Leal Ataíde; SILVA, Ingrid Fabiane Santos da; NOGUEIRA, Laura Maria Vidal. Perfil sociodemográfico e epidemiológico de uma comunidade quilombola na Amazônia Brasileira. Rev Cuid. v.9, n.2, 2018, p.2187-2200.

GOMES, Karine de Oliveira; REIS, Edna Afonso; GUIMARAES, Mark Drew Crosland; CHERCHIGLIA, Mariângela Leal. Utilização de serviços de saúde por população quilombola do Sudoeste da Bahia, Brasil. Cad. Saúde Pública. v.29, n.9, 2013, p.1829-1842.

KAMI, Maria Terumi Maruyama et al. Trabalho no consultório na rua: uso do software IRAMUTEQ no apoio à pesquisa qualitativa. Esc. Anna Nery. vol.20, n.3, 2016, p 1-5.

LOPES, Daline; DIAS, Áurea; MANSUR. Douglas. Trabalho e quilombolas: as relações de trabalho dos residentes no quilombo São José da Serra - Valença/Rio de Janeiro. Cadernos UniFOA. v.4 n. 7, 2008, p.47-53. Disponível em: http:// http://revistas.unifoa.edu.br/index.php/cadernos/article/view/907/842. Acessado em: 28 de outubro de 2019.

MOTA, Dalva Maria da; RIBEIRO, Laiane; SCHMITZ, Heribert. A organização do trabalho familiar sob a influência da produção de dendê em Tomé-Açu, Pará. Bol. Mus. Para. Emílio Goeldi. Ciênc. hum., v.14, n.2, 2019, p.531-552.

MIRANDA, Sérgio Vinícius Cardoso de; OLIVEIRA, Pâmela Scarlatt Durães; MORAES, Virlady Cardoso De Miranda; VASCONCELlOS, Luiz Carlos Fadel de. Necessidades e reivindicações de homens trabalhadores rurais frente à atenção primária à saúde. Trab. educ. saúde. v.18, n.1, 2020, p, 1-22

MORIN, Estelle; TONELLI, Maria José; PLIOPAS, Ana Luisa Vieira. O trabalho e seus sentidos. Psicol. So. v.19, n.spe 2007, p.47-56.

MOURA Pedro Filho Ferreira de; SOUZA Flávia Moreno Alves de. Qualidade de vida no trabalho $\mathrm{x}$ autorealização humana e motivação. Qualidade de vida de trabalho $\mathrm{x}$ auto-realização humana. Revista Científica - Cosmopolita em Ação. v.3 , n.2. 2016, p. Disponível em: http://revistas.icesp.br/index.php/Cosmopolita/article/view/164. Acessado em: 28 de Outubro de 2019. 
NEVES, Diana Rebello et al. Sentido e significado do trabalho: uma análise dos artigos publicados em periódicos associados à Scientific Periodicals Electronic Library. Cad. EBAPE.BR. v.16, n.2 2018, p.318-330.

OLIVEIRA, Stéphany Ketllin Mendes; PEREIRA, Mayane Moura; GUIMARAES, André Luiz Sena; CALDEIRA, Antônio Prates. Autopercepção de saúde em quilombolas do norte de Minas Gerais, Brasil. Ciênc. saúde coletiva. v.20, n.9 2015, p.2879-2890.

PRONI, Marcelo Weishaupt; GOMES, Darcilene Claudio. Precariedade ocupacional: uma questão de gênero e raça. Estud. $a v$. v.29, n.85, 2015, p.137-151.

RAMOS Maurivan Güntzel; LIMA Valderez, Marina do Rosário; ROSA, Marcelo Prado Amaral. Contribuições do software IRAMUTEQ para a Análise Textual Discursiva. Invest Qualit em Educ.; v.1, 2018, p.505-14. Disponível em: https://proceedings.ciaiq.org/index.php/ciaiq2018/article/view/1676/1628. Acessado em 28 de Outubro de 2019.

RIBEIRO, Sâniza Bezerra. Análise dos riscos ergonômicos dos trabalhadores rurais no processo de colheita. João Pessoa: Universidade Federal da Paraíba. Dissertação (Mestrado); 2005. Disponível em http://livros01.livrosgratis.com.br/cp074300.pdf. Acessado em 18 de Outubro de 2018.

SALVIATI Maria Elisabeth. Manual do Aplicativo Iramuteq. UNB - Univ Nac Bras. 2017, p. 93. Dispinível em: http://www.iramuteq.org/documentation/fichiers/manual-do-aplicativo-iramuteq-par-maria-elisabethsalviati. Acessado em 06 de Agosto de 2018.

SILVA, Roseane Amorim da; MENEZES Jaileila de Araújo. Ser mulher nas comunidades quilombolas: vivências relacionadas à família e ao trabalho. 2015 Disponível em: http://www.uneb.br/enlacandosexualidades/files/2015/07/Comunica\%C3\%A7\%C3\%A3oRoseaneAmori m.pdf. Acessado em 18 de Outubro de 2018.

SIQUEIRA Danielle; MOURA Romero Marinho de. Considerações sobre a qualidade de vida dos trabalhadores rurais em Pernambuco e a necessidade de um novo modelo de produção agrícola. Anais da Academia Pernambucana de Ciência Agronômica, 2011/2012. 42-46. Disponível em: http://www.journals.ufrpe.br/index.php/apca/article/viewFile/139/128. Acessado em 16 de Outubro de 2018.

SOUSA, Maria Sueli Rodrigues de; SANTOS, Joaquim José Ferreira dos. Territorialidade quilombola e trabalho: relação não dicotômica cultura e natureza. Rev. katálysis. v.22, n.1, 2019, p.201-209.

SORJ, Bila. Sociologia e trabalho: mutações, encontros e desencontros. Rev. Bras. Ci. Soc. v.15, n.4, 2000, p.25-34.

TOLFO, Suzana da Rosa; PICCININI, Valmíria. Sentidos e significados do trabalho: explorando conceitos, variáveis e estudos empíricos brasileiros. Psicol. soc. v.19, n.spe, 2007, p.38-46.

VERONEZZI, Fernando; SILVA, Felipe Alexandre da. A pluralidade do espaço rural de guarapuava (pr): a contribuição do povo negro e o cotidiano das famílias do quilombo "invernada paiol de telha". Revista da Associação Brasileira de Pesquisadores/as Negros/as (ABPN), [S.1.], v. 5, n. 10, 2013, p.227-242. Disponível em:

http://www.abpnrevista.org.br/revista/index.php/revistaabpn1/article/view/211. Acessado em: 21 novembro de 2019.

Recebido 30/11/2019

Aprovado em: $30 / 01 / 2020$ 